\title{
Paracetamol metabolism in patients with ulcerative colitis
}

\author{
K. V. Haderslev, ' J. Sonne, ${ }^{2}$ H. E. Poulsen ${ }^{3} \&$ S. Loft ${ }^{4}$ \\ ${ }^{1}$ Department of Gastroenterology and Internal Medicine F, Gentofte University Hospital, ${ }^{2}$ Clinical Pharmacological Unit, Gentofte University Hospital, \\ ${ }^{3}$ Department of Clinical Pharmacology, Rigshospitalet, University of Copenhagen and ${ }^{4}$ Department of Pharmacology, University of Copenhagen, Denmark
}

\begin{abstract}
Aims The capacity for sulphation of phenols appears to be impaired in the colonic mucosa of patients with ulcerative colitis. The aim of the present study was to investigate the systemic capacity for sulphation of phenols in patients with ulcerative colitis assessed by the metabolic clearances of paracetamol to the sulphate, glucuronide and glutathione derived metabolites.
\end{abstract}

Methods Ten patients with ulcerative colitis and 10 control subjects received a single oral dose of paracetamol $(1 \mathrm{~g})$. Venous blood samples were collected frequently for pharmacokinetic determinations (one compartment model). Urine was collected for $24 \mathrm{~h}$. Plasma samples were analysed for parent drug and urine samples for parent drug and metabolites by h.p.l.c. Partial metabolic clearances were calculated as the fractional urinary recovery of each conjugate multiplied by the apparent oral clearance of paracetamol.

Results The apparent oral clearance of paracetamol and the partial clearances of its metabolites were not significantly different between the two study groups. Median value and the corresponding 25th and 75th percentiles for the clearance of the sulphate metabolites were $93.6(82.5-138.8) \mathrm{ml} \mathrm{kg}^{-1} \mathrm{~h}^{-1}$ and 77.4 (75.5-99.1), patients with ulcerative colitis and control subjects, respectively.

Conclusions These results do not indicate a general impairment of the systemic capacity for sulphation of paracetamol in patients with ulcerative colitis.

Keywords: paracetamol, sulphation, ulcerative colitis

\section{Introduction}

Ulcerative colitis is a chronic inflammatory disease of unknown origin. Periods of remission alternate with periods of exacerbation, the latter often requiring intensive antiinflammatory drug treatment with 5-ASA preparations and steroids or in severe cases even colectomy. The aetiology of these relapses is unknown, and exogenous as well as endogenous factors may play a role.

The colonic lumen contains considerable amounts of phenols which are partly derived from bacterial fermentation of protein [1], and partly from xenobiotics and their metabolic products. Some of these phenols may have adverse effects in the body. Paracetamol is one xenobiotic phenol well known to possess toxicological potential, and other phenols have been shown to be tumour promoters in skin cancer [2], and have also been implicated in the development of both bladder and bowel cancer [3, 4]. Sulphation is a major conjugative pathway for detoxification and inactivation of various xenobiotics and endogenous compounds such as phenols and hormones. It takes place in most tissues although predominantly in the liver. Recently, impaired sulphation of phenols by the colonic mucosa has been shown in quiescent and active ulcerative colitis [5]. In this study paracetamol was used as model compound being a phenol and a drug mainly dependent on metabolism and

Correspondence: Dr K. Haderslev, Department of Gastroenterology CA 2121, Copenhagen University Hospital, Rigshospitalet, Blegdamsvej 9, DK-2100 Copenhagen, Denmark. inactivation by glucuronide and sulphate formation [6]. This finding makes it relevant to consider an impaired sulphation capacity of phenols of the colonic mucosa in ulcerative colitis to be one possible pathogenetic prerequisite for active disease. This is further supported by the observation, that relapses of ulcerative colitis have been associated with preceding intake of paracetamol [7]. Whether the impaired sulphoconjugation of paracetamol is restricted to the abnormal colonic mucosa or is constitutional in patients with ulcerative colitis remains to be investigated. In the present study the systemic sulphation of paracetamol was investigated in patients with ulcerative colitis and controls.

\section{Methods}

Ten outpatients with established ulcerative colitis, two men and eight women, and 10 healthy control subjects, four men and six women, participated in the study after giving informed consent. The study was approved by the ethics committee of Copenhagen County. The median age and body weight of patients and controls were 52.5 (45.0-63.0) and $33.5(30.0-38.0)$ years, and $65.0(64.0-80.8)$ and 75.0 $(66.0-80) \mathrm{kg}$, respectively. The diagnosis of the ulcerative colitis patients was based on clinical, histological, and radiological or endoscopic criteria. None of the patients had undergone bowel surgery. The disease in all patients was considered inactive. Two patients were treated with topical steroids, and one was treated with oral prednisolone due to minor relapses several weeks prior to the study. None of 
the patients or control subjects had a daily intake of alcohol. On the study day and the preceding day all refrained from taking any drugs except the prescribed medication.

Following an overnight fast each subject received a single oral dose of $1 \mathrm{~g}$ paracetamol (two $500 \mathrm{mg}$ tablets paracetamol with $100 \mathrm{ml}$ water). A light meal was allowed $2 \mathrm{~h}$ after the dose. Venous blood samples were taken at 0 (predose) and $1,2,3,4$ and $6 \mathrm{~h}$ after dosage via an indwelling cannula. Plasma was separated after centrifugation of blood samples and stored at $-20^{\circ} \mathrm{C}$. Urine was collected for $24 \mathrm{~h}$ after the administration of paracetamol, and aliquots of urine were stored at $-20^{\circ} \mathrm{C}$. Plasma samples were analysed for parent drug and urine samples for parent drug and metabolites by h.p.l.c [8]. Glucuronide, sulphate and glutathione derived metabolites in urine were assayed in duplicate, and coefficients of variation were $2.5 \%, 3.1 \%$ and $6.2 \%$, respectively.

\section{Pharmacokinetic analysis}

The area under the plasma drug concentration vs time profile (AUC) was calculated according to the linear trapezoidal rule up to the end of sampling using a computer program (EXCEL, Microsoft inc.), and adding the remaining area which was extrapolated to infinity using the terminal $\log$ drug concentration-time slope. The fraction of the AUC extrapolated was on average $16.2 \%$.

In the absence of an exact measurement of bioavailability in this study the systemic clearance of paracetamol could not be assessed accurately. However, paracetamol is normally well absorbed, and the total urinary recovery of paracetamol and its conjugates is $\approx 85-90 \%$ of the dose [9, 10]. Thus, the systemic clearance is almost equal to the apparent oral clearance $\left(\mathrm{CL}_{\mathrm{po}}\right)$ which was estimated from:

$$
\mathrm{CL}_{\mathrm{po}}=\frac{\text { Dose }}{\mathrm{AUC} \cdot \text { Bodyweight }} .
$$

The plasma elimination half-life $\left(t_{1 / 2}\right)$ of paracetamol was estimated by linear regression of the terminal log drug concentration values $\left(k_{\mathrm{e}}\right)$.

$$
t_{1 / 2}=\frac{\ln 2}{k_{\mathrm{e}}}
$$

The renal clearance of paracetamol and the partial clearance to the glucuronide and sulphate metabolites were calculated from the apparent oral clearance of paracetamol multiplied by the fraction of the dose excreted in urine as the metabolite in $24 \mathrm{~h}$. Partial clearance down the glutathione pathway was calculated likewise from the fraction of the sulphur containing paracetamol metabolites (cysteine$\mathrm{P}+$ mercapturate-P) recovered in urine multiplied by the apparent oral clearance of paracetamol.

\section{Statistics}

Statistical comparisons were made using the Mann-Whitney rank sum test for unpaired observations taking the critical value of $P$ as 0.05 . Values are expressed as median and 25 th -75 th percentiles. The study was designed with sufficient power to detect a $40 \%$ difference in the total clearance of paracetamol and the partial clearances of its metabolites. The EXCEL statistical program (Microsoft inc.) was used for all analyses.

\section{Results}

Patients with ulcerative colitis were significantly older than the control subjects, but there was no difference in median weight between the two groups. The pharmacokinetic parameters for paracetamol disposition, and data on the urinary excretion and the partial metabolic clearances in patients and controls are shown in Table 1. The median value of the apparent oral clearance of paracetamol in patients with ulcerative colitis did not differ significantly from the controls. In addition, there was no significant difference in the urinary excretion of any metabolite,

\begin{tabular}{|c|c|c|c|}
\hline & Ulcerative colitis & Controls & $\begin{array}{c}95 \% \mathrm{CI} \text { of } \\
\text { median difference }\end{array}$ \\
\hline \multicolumn{4}{|l|}{ Pharmacokinetic parameter } \\
\hline $\operatorname{AUC}\left(\mathrm{mg} \mathrm{l}^{-1} \mathrm{~h}\right)$ & $46(37-53)$ & $43(34-55)$ & $-14-12$ \\
\hline$t_{1 / 2}(\mathrm{~h})$ & $1.9(1.7-2.1)^{\star}$ & $2.4(1.9-2.5)$ & $-0.9--0.1$ \\
\hline $\mathrm{CL}_{\mathrm{po}}\left(\mathrm{ml} \mathrm{h}^{-1} \mathrm{~kg}^{-1}\right)$ & $316.0(256.7-358.2)$ & $319.0(275.4-348.1)$ & $-86.9-60.2$ \\
\hline \multicolumn{4}{|c|}{ Excretion of metabolites (\% of dose) } \\
\hline Sulphate & $35(25-37)$ & $26(23-34)$ & $-1.3-13.4$ \\
\hline Glucuronide & $53(48-56)$ & $61(55-68)$ & $-15.6-2.5$ \\
\hline Glutathione derivatives & $9(8-11)$ & $8(7-12)$ & $-2.7-2.7$ \\
\hline Paracetamol & $3(2-3)$ & $3(2-4)$ & $-1.4-0.9$ \\
\hline \multicolumn{4}{|c|}{ Clearance to metabolite $\left(\mathrm{ml} \mathrm{h}^{-1} \mathrm{~kg}^{-1}\right)$} \\
\hline Sulphate & $93.6(82.5-138.8)$ & $77.4(75.5-99.1)$ & $-4.8-44.8$ \\
\hline Glucuronide & $150.1(123.4-210.4)$ & $189.0(153.7-212.4)$ & $-80.0-44.0$ \\
\hline Glutathione derivatives & $31.5(21.5-36.3)$ & $26.3(23.1-30.0)$ & $-6.7-12.0$ \\
\hline Paracetamol & $8.2(6.6-14.1)$ & $8.8(7.5-11.6)$ & $-3.7-5.3$ \\
\hline
\end{tabular}
expressed either as a percentage of the dose or clearance to

Table 1 Pharmacokinetic parameters for the disposition of paracetamol and urinary excretion of paracetamol metabolites in 10 patients with ulcerative colitis and 10 control subjects. Results are median and 25 th -75 th percentiles.

${ }^{\star}$ Significantly different from controls, $P<0.05$, Mann-Whitney rank sum test. 
the metabolite. The terminal plasma half-life differed significantly between the two groups $(P<0.05)$. The median recovery expressed as the percentage of the dose recovered in the urine in $24 \mathrm{~h}$ was $89.6 \%$ in patients and $64.0 \%$ in controls, $(P>0.05)$.

\section{Discussion}

The paper by Ramakrishna et al. [5] raised theoretically an important question whether the demonstrated low sulphation capacity of the colonic mucosa is a local or constitutional phenomenon. Other disease states have been associated with a lower urinary excretion of the sulphate conjugate of paracetamol [11-13], and low levels of the enzyme phenol-sulphotransferase, reduced amounts of inorganic sulphate or decreased formation of 3 '-phosphoadenosine- 5 'phosphosulphate (PAPS) have been proposed as possible explanations in these conditions. The present study gives no indication of a systemic impairment of the metabolism of oral administered paracetamol to the sulphate metabolite in patients with ulcerative colitis. In fact the fractional urinary recovery and clearance of each metabolite was very similar to those of the controls, and to reference values obtained in larger studies on paracetamol metabolism in healthy Caucasian adults $[9,10]$. In addition, the apparent oral clearance of paracetamol was similarly comparable with the reference value $[10,14]$ in both patients and controls. The elimination half-life appeared to be significantly lower in patients than in controls, but given that the volume of distribution could not be accessed in this peroral study it is, however, difficult to interpret the significance of this finding. Thus, the apparent oral clearance, which in this study was of equal size in patients and controls, is considered a better parameter for metabolic capacity than elimination half-life. Although the elimination half-life was somewhat lower in patients with ulcerative colitis compared with the controls in our study, the value is still comparable with accepted reference values in healthy adults [9, 10, 14].

There was a difference in age distribution between the two groups, patients with ulcerative colitis being significantly older than controls. Still, there is no evidence for agerelated differences in the overall elimination rate constant for paracetamol in the age group relevant to our study [15, 16]. It is, however, known that very late in life a smaller amount of paracetamol is biotransformed to the sulphate metabolite. Miners et al. [17] found a $23.1 \%$ reduction in clearance to the sulphate metabolite in men aged 72-92 years compared with younger men with mean age 20.8 years.

Ramton et al. [7] found a high prevalence of paracetamol ingestion before relapse of ulcerative colitis, and the association was even more striking when higher doses of paracetamol had been taken. However, this surprising association has not been confirmed by other investigators, and at 2 months follow up none of the patients in the present study had developed active disease due to the paracetamol ingestion in relation to the study. Possible explanations for a relationship between paracetamol ingestion and relapse of ulcerative colitis have been focused on the systemic effects of paracetamol, i.e. drug-induced prostaglandin deficiency leading to loss of mucosal cytoprotection, or increased bleeding secondary to defective platelet function
[7]. Yet another possible mechanism could involve a local injurious effect on the colonic mucosa of non absorbed paracetamol, considering that the local detoxification of paracetamol appears to be impaired in these patients [5].

Despite the relatively few participants in the present study, the fact that patients had partial clearances to all metabolites of paracetamol comparable with controls make clinically relevant metabolic changes of the sulphation pathway in patients with ulcerative colitis very unlikely. Since the colon is exposed to xenobiotic phenols ingested with food and locally from bacterial fermentation of proteins [1], further study of the mechanism of the low sulphation capacity of the colonic mucosa is warranted. These compounds may possess toxicological potential and may be incriminated as one possible explanation to relapses in ulcerative colitis.

The technical assistance of Jytte Purtoft is greatly appreciated.

\section{References}

1 MacFarlane GT, Allison C. Utilisation of protein by human gut bacteria. FEMS Microbiol Ecol 1986; 38: 19-24.

2 Boutwell RK, Bosch DK. The tumor-promoting action of phenol and related compounds for mouse skin. Cancer Res 1959; 19: 413-427.

3 Bryan GT. The role of urinary tryptophan metabolites in the etiology of bladder cancer. Am J Clin Nutr 1971; 24: 841-847.

4 Bingham SA. Meat, starch, and nonstarch polysaccharides and large bowel cancer. Am J Clin Nutr 1988; 48 (Suppl): 762-767.

5 Ramakrishna BS, Roberts Thomson IC, Pannall PR, Roediger WE. Impaired sulphation of phenol by the colonic mucosa in quiescent and active ulcerative colitis [see comments]. Gut 1991; 32: 46-49.

6 Cummings AJ, King ML, Martin BK. A kinetic study of drug elimination: the excretion of paracetamol and its metabolites in man. Br J Pharmacol 1967; 29: 150-157.

7 Rampton DS, McNeil NI, Sarner M. Analgesic ingestion and other factors preceding relapse in ulcerative colitis. Gut 1983; 24: 187-189.

8 Poulsen HE, Lerche A, Pedersen NT. Phenobarbital induction does not potentiate hepatotoxicity but accelerates liver cell necrosis from acetaminophen overdose in the rat. Pharmacology 1985; 30: 100-108.

9 Critchley JA, Nimmo GR, Gregson CA, Woolhouse NM, Prescott LF. Inter-subject and ethnic differences in paracetamol metabolism. Br J Clin Pharmacol 1986; 22 : 649-657.

10 Forrest JA, Clements JA, Prescott LF. Clinical pharmacokinetics of paracetamol. Clin Pharmacokinet 1982; 7: 93-107.

11 Steventon GB, Heafield MT, Waring RH, Williams AC, Sturman S, Green M. Metabolism of low-dose paracetamol in patients with chronic neurological disease. Xenobiotica 1990; 20: $117-122$.

12 Bradley H, Waring RH, Emery P, Arthur V. Metabolism of low-dose paracetamol in patients with rheumatoid arthritis. Xenobiotica 1991; 21: 689-693.

13 Kamali F, Thomas SH, Ferner RE. Paracetamol elimination in patients with non-insulin dependent diabetes mellitus. $\mathrm{Br}$ J Clin Pharmacol 1993; 35: 58-61.

14 Mucklow JC, Fraser HS, Bulpitt CJ, Kahn C, Mould G, Dollery CT. Environmental factors affecting paracetamol 
metabolism in London factory and office workers. $\mathrm{Br} \mathrm{J}$ Clin Pharmacol 1980; 10: 67-74.

15 Divoll M, Abernethy DR, Ameer B, Greenblatt

DJ. Acetaminophen kinetics in the elderly. Clin Pharmacol Ther 1982; 31: 151-156.

16 Miller RP, Roberts RJ, Fischer LJ. Acetaminophen elimination kinetics in neonates, children, and adults. Clin Pharmacol Ther 1976; 19: 284-294.
17 Miners JO, Penhall R, Robson RA, Birkett DJ. Comparison of paracetamol metabolism in young adult and elderly males. Eur J Clin Pharmacol 1988; 35: 157-160.

(Received 5 January 1998, accepted 29 May 1998) 